\title{
"ARE THEY REALLY SATISFIED?": AN EXPLORATION OF ISSUES AROUND EMPLOYEE SATISFACTION ASSESSMENT STRATEGIES
}

\author{
MICHAEL TOWNSEND \\ ERROL SUNDELOWITZ \\ KAREL STANZ \\ karelss@uj.ac.za \\ Department of Human Resources Management \\ University of Johannesburg
}

\begin{abstract}
The aim of the study was to conduct an exploration into the issues around the employee satisfaction strategy and tool being utilised by a large public utility in South Africa. A mixed method approach was applied incorporating focus groups, individual interviews, and a questionnaire. The results indicate that staff are not satisfied with the existing strategy, are reasonably comfortable with the dimensions being measured but clearly want to see a qualitative aspect added. Major areas of concern are: lack of feedback, little or no action plans linked to the results and a lack of a genuine concern for employee satisfaction.
\end{abstract}

Key words

Employee satisfaction, instrument evaluation, mixed methods

"... managers are seen to be always looking up and never looking down. In other words, the focus is on achieving Key Performance Indicators (KPI's) and listening to what senior management were saying while believing that the work will just get done" (Townsend, 2006c).

This is typical of feedback received from employees during the course of the research study on which this article is based. It is feedback of this ilk which immediately raised doubts regarding the existing Employee Satisfaction strategy and tool that is presently being used by The Organisation and has been in use for many years. It is comments such as the above that have raised the question,"Is The Organisation's Employee Satisfaction strategy effective and is it worth pursuing into the future"? It is towards answering this question that this article is focussed. The guiding definition of Employee Satisfaction to be used in this article will be, "the degree to which the individuals needs and desires are met and the extent to which this is perceived by the other employees" (Küskü, 2003, as cited in Samuel, 2005, p13).

Employee Satisfaction was a much popularised subject during the 1980's and 1990's, where much of the literature (Stoner \& Wankel, 1986; Brewster, Dowling, Grobler, Holland \& Warnich, 2000), focused on the link between Employee Satisfaction and Employee Performance. Subsequent research has, however, proven that this link is not particularly strong, (Kreitner \& Kinicki, 2005; Ivancevich \& Matteson, 2002). What recent research has confirmed is that there is a clear reciprocal relationship between Employee Satisfaction and Customer Satisfaction (Kraut, 1996). For example, one of the most detailed studies undertaken was that carried out by Heskett, Sasser, Jr. and Schlesinger (1995). The authors point out that, "When companies put employees and customers first, their employees are satisfied, their customers are loyal, their profits increase, and their continued success is sustained" (as cited in Bailey \& Dandrade, 1997, p3).

The organisation in which this research project has been conducted (hereafter referred to as The Organisation) has acknowledged this fact and actively measures and monitors the levels of satisfaction in both cases. This is done by utilising two measurement tools, namely: the Employee Satisfaction Index (ESI) and from a Customer Satisfaction perspective, Maxicare (The Organisation, 2006). What is of concern is that the two measurement tools are not linked in any way and are used in isolation by two different departments within The Organisation.

As far as Employee Satisfaction within The Organisation is concerned, the existing process was launched approximately fifteen years ago. This process, and the tool used to monitor satisfaction levels, were developed based on the results of a literature study completed at the time (Benkenstein, 2006). On being consulted regarding his source documents and literature review, the designer indicated this information had long since been disposed of (ibid; email communication).

Supporting documentation or other archival traces from which to examine the tool in terms of the validity and reliability of its construction now no longer exist. There was therefore no means of examining the soundness of the existing instrument. This is especially in terms of how it had been constructed, normed and consequently adopted as a central means of assessing Employee Satisfaction within The Organisation.

This current research project was conducted from the standpoint that there was considerable doubt that the abovementioned strategy provided an adequately true and effective reflection of the status of Employee Satisfaction in The Organisation. This was supported by the increasing time and effort that had to be exerted to ensure a similar percentage return year on year (internal Employee Satisfaction Index reports, 2003-2005). The current Employee Satisfaction Assessment process was also coming under increasing criticism from both managers and the labour force. Very common feedback received from both members of the labour force and management was that the instrument had run its course and that the vast majority of staff in The Organisation did not see the value that this instrument and the process attached to it was bringing to The Organisation (internal Employee Satisfaction Index reports, 2003-2005). It was also very difficult to defend from an academic point of view due to the lack of archival support.

Since being implemented the ESI assessment process has been converted to an electronic exercise. Many employees in The Organisation do not have access to the intranet and, therefore a manual exercise still exists for a large percentage of the labour force. This throws doubt on the whole process from a confidentiality point of view as in most cases the supervisor facilitates the completion of the questionnaires by his/her subordinates. Employees make requests on an ongoing basis for a facility to provide ad hoc comments. During the last three years an average return of roughly $50 \%$ has been maintained and a drop in Employee Satisfaction from $71 \%$ to $69 \%$ has been noted (internal Employee Satisfaction Index survey reports, 2003-2005). There also appears to be a year on year decrease in satisfaction levels in respect of Colleagues and Diversity dimensions. 
The concept of Employee Satisfaction can be traced back to Edward Thorndike, who in the early 1900's published an article in the Journal of Applied Psychology where he explored the relationship between work and satisfaction (Bavendam, 2000). The concept of Employee Satisfaction has certainly been researched very thoroughly over the years and has been linked to many other issues like employee loyalty, employee commitment, employee engagement and job satisfaction Fosam, Grimsley \& Wisher, 1998; Martensen \& Grønholdt, 2002).

One of the most quoted theorists is Hertzberg (1968) who during the 1950's developed his theory which identified two dimensions of satisfaction, namely motivation and hygiene. Hertzberg (1968) maintained that the hygiene factors could not motivate employees but rather helped minimise dissatisfaction levels if addressed. These hygiene factors include topics such as; company policies, supervision, salary, interpersonal relationships and working conditions. The motivating factors addressed topics such as: the work itself, achievement, recognition, responsibility, and advancement. If continuously good levels are maintained in respect of these topics, a motivated work force is created.

It is unlikely that Hertzberg (1968)'s theory in its original form is totally relevant in today's radically different world of work. This is particularly so in a country like South Africa where strategic focuses like racial and gender equity are legislated and audited by national government. This standpoint has been researched by Janse van Rensburg (2004) who identified a clear link between employee satisfaction/ commitment and the implementation of these types of programs. The Organisation concerned makes use of a strategy and tool which focuses on 14 dimensions (see Table 1 below). A superficial analysis of these dimensions indicates an obvious alignment with Hertzberg's hygiene factors.

\section{TABLE 1}

THE ORGANISATIONS EMPLOYEE SATISFACTION DIMENSIONS COMPARED TO HERTZBERG (1968)'S FIMENSIONS AND FACTORS

\begin{tabular}{ll}
\hline The Organisation's 14 dimensions & Hertzberg's dimensions and factors \\
\hline Supervision & Hygiene factor \\
My Job & Motivating factor \\
Personal Development & Motivating factor \\
Colleagues & Hygiene factor \\
Work Place & Hygiene factor \\
Policies and Procedures & Hygiene factor \\
Communication & Hygiene factor \\
Remuneration & \\
Transformation & \\
Performance Management & \\
Diversity & \\
Ethics & \\
Respect & \\
Commitment to Customer Service & \\
\hline
\end{tabular}

The first seven dimensions were part of the original tool developed by the designer some fifteen years ago (Benkenstein, 2006). Subsequent to that, the Remuneration, Transformation, Performance Management, Diversity and Respect dimensions were added. Lastly the dimensions of Ethics and Commitment to Customer Service were added. The addition of these dimensions was based on the request of management to align with key focus areas in the business, and not because they were identified based on feedback received from employees as being crucial to employee satisfaction.

Although Hertzberg's (1968) theory is considered central to the concepts of Employee Satisfaction, it is important not to look at Employee Satisfaction in isolation, but to rather consider it as an integral part of the process of ensuring satisfied customers and a profitable business. For example, Vilares and Cohelo (2000) developed a model (see Figure 1 below) based on their findings which supported the link between employee satisfaction and customer satisfaction (as cited by Bulgarella, 2005, p.2). Heskett et al (1997) carried out comprehensive research from which they developed the Service-Profit Chain (see Figure 2 below).

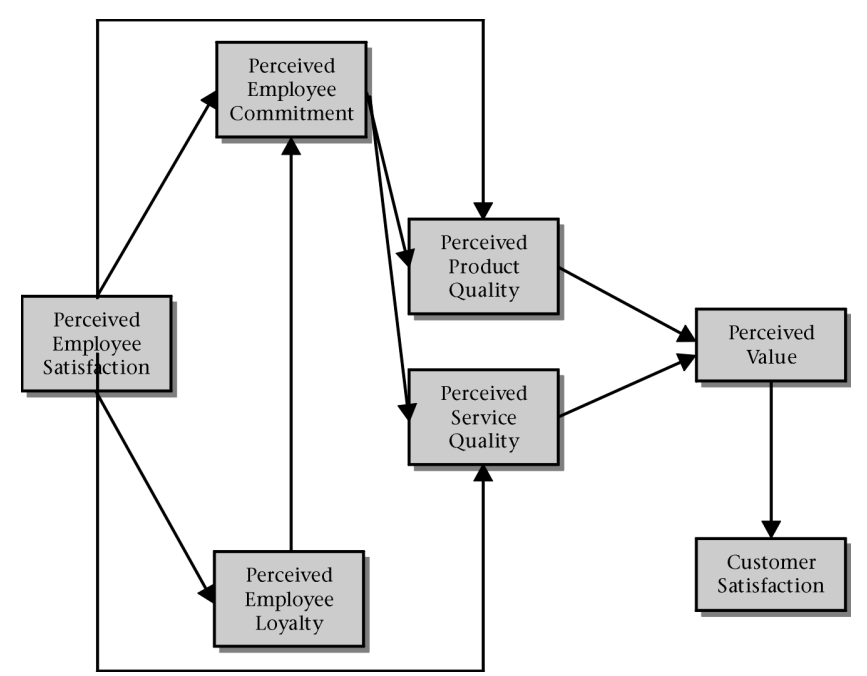

Figure Figure 1: Employee Satisfaction Model Source: Vilares \& Cohelo (2000)

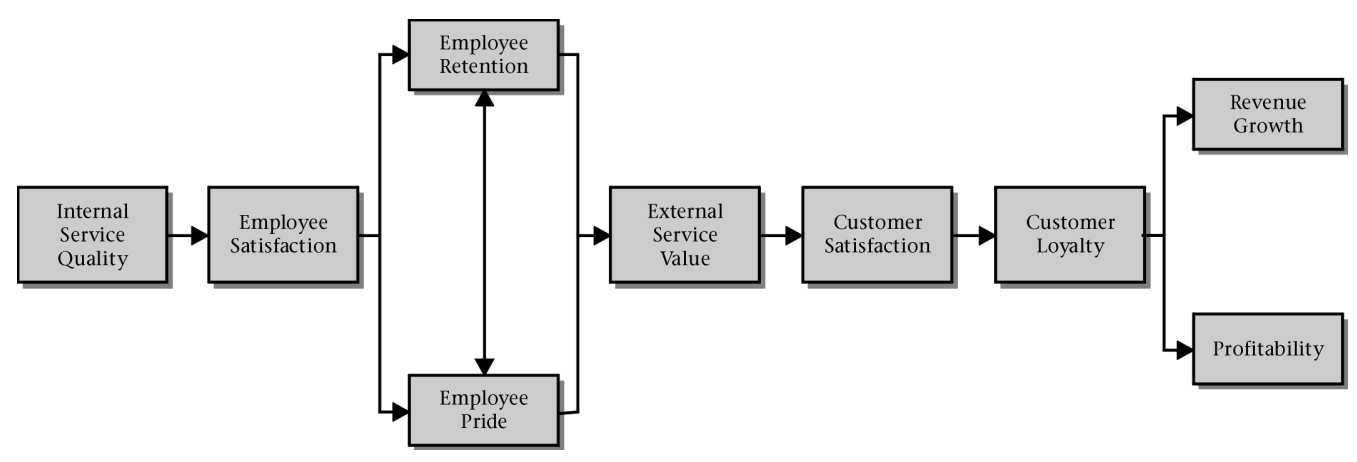

Figure 2: The Service Profit Chain

Source: Heskett, Sasser, Jr \& Schlesinger (1997) 


\section{RESEARCH DESIGN}

Research Approach

The concept of employee satisfaction within The Organisation is one which has been neglected for quite some time. It is also believed that the current process is not taking care of key stakeholders' needs as a result of radical changes which have taken place over the last number of years. The context within The Organisation is complex and although a single reality exists with respect to the issue it will be necessary to embark on a comprehensive and rigorous study to establish the necessary information to address the problem. Concomitant with the complexity of the context within The Organisation, the research paradigm that has been selected to inform the research process is that of Critical Realism. This is also sometimes referred to as PostPositivism (Denzin \& Lincoln, 2005) or Neo-Post-Positivism (Manicas \& Secord, 1982).

This paradigm maintains that it is practically impossible to be totally objective and that subjectivity is inevitable. From a critical realist point of view reality is "real" but only imperfectly so. This is based on the viewpoint that reality is based on individual perceptions of reality and that reality is a result of social conditioning. In order to try and get to know what the current reality is it is, therefore, important to make use of many different sources. This approach incorporates the use of both qualitative and quantitative methods to aid triangulation of data and hence ensure a more rigorous process in coming to grips with reality. "The idea behind triangulation is that the more agreement of different data sources on a particular issue, the more reliable the interpretation of the data," (Cano, n.d., p.4). In order to remain as objective as possible throughout the research project the researcher continuously assessed the influence they were having on the research process.

An integral part of the qualitative approach that was adopted was the use of focus groups. This is in alignment with a phenomenological approach where the feelings and emotions of stakeholders within The Organisation were recorded as accurately as possible. In heeding Boeree's (1998) warning that there is a danger that the interviewer may influence the feedback received from the participants, bracketing was used to counter the influence of researcher bias in the process. Semi-structured interviews (del Barrio, 1999) were utilised to obtain specific information to inform the structuring of the Focus Group questions as well as to ensure management support for the entire study. In addition, a short questionnaire was administered via The Organisation's intranet to obtain feedback from employees regarding the effectiveness of the existing tool and to get input regarding dimensions which should be measured. Prior to initiating the process of participant selection and data collection, written consent was obtained from The Organisation and ethical confidentiality procedures guaranteed. An undertaking to provide feedback to The Organisation regarding the research results was also agreed to.

\section{Participants}

Participants were selected from the Southern Region of The Organisation. This was done from a pool of potential participants consisting of 1456 employees with roughly one third of these employees based at the Regional Head Office in East London. Five focus groups were conducted and included inputs from 48 individuals. As far as the questionnaire based survey is concerned, a sample of 428 was achieved. This equates to a return of $29 \%$ and includes inputs from employees across all job grades and geographical areas in the region. Further data was located in the archival records of The Organisation.
TABLE 2

NUMBER OF PARTICIPANTS PER GRADE

\begin{tabular}{lcc}
\hline Grade (Patterson) & Number of returns & \% return \\
\hline B bands & 108 & $15 \%$ \\
C bands & 280 & $43 \%$ \\
D bands & 40 & $53 \%$ \\
Total & 428 & \\
\hline
\end{tabular}

Data was gathered by carrying out archival research, conducting a questionnaire based survey (a first step analysis here was done using a four point likert scale), carrying out a rigorous literature study, conducting structured interviews and by conducting focus groups. This facilitated triangulation of data through eliciting input from as broad a spectrum of sources as possible. The questionnaire consisted of six questions addressing the following dimensions: Management Commitment, Administration of the Process, The Process of Giving Feedback, The Perceived Accuracy of the Results, The Validity of the Dimensions and An Opinion on Whether Comments Fields Should Be Included. The likert scale that was used in the questionnaire was: Strongly Disagree, Disagree, Agree, Strongly Agree.

Focus groups were chosen to afford managers and the labour force an opportunity to provide input regarding their needs concerning Employee Satisfaction. According to David L. Morgan (1988, p.9),

As a form of qualitative research, focus groups are basically group interviews, although not in the sense of an alternation between the researchers' questions and the research participants' responses. Instead, the reliance is on interaction within the group, based on topics that are supplied by the researcher, who typically takes the role of a moderator.

It is understood that although focus groups have become increasingly popular especially outside of the marketing and sales arena, there were a number of issues which needed to be borne in mind. Uppermost in this list was possibly the influence that the facilitator may have on the focus group (group interview) process. This was particularly relevant in this case where the focus group facilitator had strong opinions regarding the issue under discussion and may have inadvertently led or steered the group towards his way of thinking (Boeree, 1998). Other issues which guided the running of the focus groups were those of the influence of strong personalities, group think and the risk of the session ending in an emotional chat show.

Four focus groups were conducted with staff across the regions four geographical areas. One additional focus group was conducted at Head Office aimed specifically at managers only. In addition, historical records of the last three employee satisfaction surveys were analysed for trends and themes. Lastly, an electronic quantitative questionnaire was initiated via The Organisations intranet facility to obtain additional feedback concerning the existing employee satisfaction strategy and tool.

The archival records of the internal Employee Satisfaction Index survey for the last three years (2003-2005) were utilised to assess trends and themes and the original developer of the existing tool was engaged to obtain as much information as possible regarding the development of the tool. Rosnow and Rosenthal (1996, p.80) cite archival records as an example of unobtrusive, non-invasive observation, and they define "an archive" as "any relatively permanent repository of data or material". Archival records provided a further means of identifying central issues for the present study. 


\section{Analysis of the Data}

Data that is produced in research conducted under the paradigm of Critical Realism should be the result of a robust multidimensional data collection process (Krauss, 2005). This should be a process whereby large quantities of data are accumulated via a number of different methodologies to ensure triangulation. For this type of research triangulation means comparing several perceptions of reality so as to acquire a better understanding of reality. It helps ensure that a more realistic reflection of what the true reality is, is obtained (Krauss, 2005). The feedback received via the focus groups was subjected to a systematic coding via content analysis as suggested by Morgan (1988) and identified themes were noted. The information obtained via this process was collated and compared to the findings obtained from the literature review as well as the quantitative process via the questionnaire.

To address the issue of validity in the research project a rigorous process was ensured. This was maintained mainly through the abovementioned methods of triangulation to ensure as broad a spread of methods as possible. Critical to the validity of the research was the element of trustworthiness. This refers to the information obtained from the research as well as maintaining the anonymity of the research participants. It was therefore important for the entire process to be transparent in respect of the purpose of the study, what would happen to the information obtained from the participants and a fair and accurate representation of the information contained in the finished article (Golafshani, 2003).

From a validity point of view, it is important that what is represented in a report on the findings accurately matches the stories told or as perceived by the participants. ". . the purpose of qualitative research is to describe or understand the phenomena of interest from the participant's eyes, the participants are the only ones who can legitimately judge the credibility of the results," (Trochim, 2005, p.1). Credibility here can be equated with the concept of validity for the purpose of the present study.

\section{FINDINGS}

A central issue arising out of the feedback from the management focus group (Townsend, 2006b) is that the existing strategy and tool has run its course in its existing format. This fact was borne out by the feedback from the managers who participated in the management level focus group. They felt that there was not enough credence given to the fact that the questionnaire is just one tool to assist managers in determining employee satisfaction levels. For many managers the questionnaire had become the one and only tool and if the result was above the target they were happy. The management focus group participants felt that it was time to look for a fresh approach, one which could accommodate a more flexible approach with open ended questions, and which would assist managers establish employee needs more realistically. They felt very strongly about the fact that due to the amount of time and effort required to generate a valid result for the employee satisfaction survey, it was critical that the information obtained should be properly assessed and utilised to identify employees' real needs. This feedback is in line with the initial perception that management had grown increasingly frustrated with the existing strategy.

Participants in the general employee focus groups (Townsend, 2006c) also felt that the employees no longer understood the reason for the survey and a process of re-sensitisation needed to be embarked on to rectify this. This information was supported by feedback received from employees who indicated that the purpose for the survey had long been forgotten. A basic requirement for conducting any survey is that the people being requested to participate need to understand the purpose for the survey and how it will be of benefit to them (Leones, 1998). This is clearly not being done in this case. The fact that the survey is only conducted on an annual basis was of concern in that a more frequent survey with appropriate consequences would benefit both management and employees. This was also an issue raised by both managers and employees (Townsend, 2006d) even though both parties conceded that there are certainly difficulties arising out of a more frequent survey from a time point of view.

"The managers don't care about us" would typify the perception that employees have of management (Townsend, 2006c). The employees feel that a large emphasis is placed on achieving Key Performance Indicators (KPI's) regardless of the impact on manpower. The employee satisfaction survey exercise is a case in point where employees are badgered into completing the questionnaire so that a result can be generated, but the staff don't get any feedback or see any consequences.

At the end of the day managers should be, of their own accord, doing things on an on-going basis to establish employees needs and - probably more importantly - what needs to be done to meet these needs if they are not being met. This is something that should be happening on an on-going basis and the annual employee satisfaction survey should be used as a checkpoint.

The most common feedback received out of the general staff focus groups regarding the survey itself, centred around a lack of feedback and follow-through from management (Townsend, 2006c). Employees maintain they are tired of being called upon time and again to complete employee satisfaction survey questionnaires and yet nothing essentially changes in the status quo. They believe that the only reason the survey is conducted annually is to obtain a result for the managers' performance appraisals. They do not believe that there is a genuine interest from managers regarding employee satisfaction. This is a clear indication that management do not understand the potential value in following through on the data generated via the survey.

Employees also requested that they be afforded the opportunity to give more general feedback in addition to being asked to assess specific dimensions. To cater for this it is suggested that geographically based area focus groups be established. Once again there is a clear need for a more qualitative process when dealing with employee satisfaction. This is particularly true when it comes to accommodating the varying needs of different grades, race groups and gender.

A number of common themes were identified in the analysis of the available archival data. Firstly, it is becoming increasingly difficult to achieve sufficient sample sizes from certain areas within The Organisation. This is particularly true of the Engineering environment and specifically Department A and Department B. Secondly, there is very little enthusiasm or energy being demonstrated by management in terms of actively supporting the process. Thirdly, increasing numbers of employees are requesting an opportunity to give more open ended responses in addition to being asked to assess specific dimensions (that is a more qualitative approach). Fourthly, employees are becoming increasingly uncomfortable with completing the hardcopy questionnaires, as the process is inevitably facilitated by their supervisor and they are hindered by the lack of confidentiality.

An assessment of the data accumulated via the questionnaire based survey (Townsend, 2006e), indicate that there are many participants who do not believe that management is fully committed to employee satisfaction. This is particularly valid in Department A where only $31 \%$ of employees are satisfied with this element of the process. What is significant here is 
that the vast majority of employees (400) are situated within this department including many lower level employees. It is also interesting to note that management maintain that they are committed to the process. This could indicate that either management are not clearly demonstrating their commitment in a practical way, or employees' expectations are much higher than anticipated. Most participants are satisfied with the administrative process and a vast majority of employees (87\%) across all grades supported the need to allow participants to submit comments when completing the employee satisfaction survey. This fully supports the feedback received via the focus groups. The employees agreed that feedback was not done appropriately whereas management felt they were giving appropriate feedback and there is also considerable doubt illustrated in respect of the accuracy of the results.

TABLE 3

Percentage agree per dimension, per total region, ENGINEERING ENVIRONMENT, FIELD SERVICES DEPARTMENT AND ELECTRICITY DELIVERY DEPARTMENT

\begin{tabular}{|c|c|c|c|c|}
\hline Dimension & $\begin{array}{c}\text { Total Region } \\
\text { Sample }=428 \\
(29 \%)\end{array}$ & $\begin{array}{c}\text { Engineering } \\
\text { Sample }= \\
206\end{array}$ & $\begin{array}{c}\text { Department } \\
\text { A Sample = } \\
85\end{array}$ & $\begin{array}{c}\text { Departmen } \\
\text { B Sample = } \\
42\end{array}$ \\
\hline $\begin{array}{l}\text { Management } \\
\text { commitment }\end{array}$ & $53 \%$ agree & $45 \%$ agree & $39 \%$ agree & $38 \%$ agree \\
\hline $\begin{array}{l}\text { Administrative } \\
\text { process }\end{array}$ & $80 \%$ agree & $82 \%$ agree & $80 \%$ agree & $86 \%$ agree \\
\hline $\begin{array}{l}\text { Feedback } \\
\text { process }\end{array}$ & $47 \%$ agree & $44 \%$ agree & $43 \%$ agree & $38 \%$ agree \\
\hline $\begin{array}{l}\text { Accuracy of s } \\
\text { result }\end{array}$ & $50 \%$ agree & $48 \%$ agree & $50 \%$ agree & $43 \%$ agree \\
\hline $\begin{array}{l}\text { Current } \\
\text { dimensions }\end{array}$ & $65 \%$ agree & $66 \%$ agree & $69 \%$ agree & $69 \%$ agree \\
\hline Comments & $87 \%$ agree & $87 \%$ agree & $85 \%$ agree & $90 \%$ agree \\
\hline
\end{tabular}

TABLE 4

Percentage agree Per dimension, Per band

\begin{tabular}{lccc}
\hline Dimension & $\begin{array}{c}\text { B Bands } \\
\text { Sample }=\mathbf{1 0 8}\end{array}$ & $\begin{array}{c}\text { C Bands } \\
\text { Sample }=\mathbf{2 8 0}\end{array}$ & $\begin{array}{c}\text { D Bands } \\
\text { Sample }=40\end{array}$ \\
\hline $\begin{array}{l}\text { Management c } \\
\text { ommitment }\end{array}$ & $58 \%$ agree & $50 \%$ agree & $77 \%$ agree \\
$\begin{array}{l}\text { Administrative } \\
\text { process }\end{array}$ & $82 \%$ agree & $81 \%$ agree & $83 \%$ agree \\
$\begin{array}{l}\text { Feedback process } \\
\text { Accuracy of results }\end{array}$ & $50 \%$ agree & $43 \%$ agree & $70 \%$ agree \\
$\begin{array}{l}\text { Current } \\
\text { dimensions }\end{array}$ & $48 \%$ agree & $61 \%$ agree & $63 \%$ agree \\
Comments & $91 \%$ agree & $86 \%$ agree & $63 \%$ agree \\
\hline
\end{tabular}

\section{DISCUSSION}

From a literature study point of view, the dimensions currently included in the existing tool are all relevant as far as employee satisfaction is concerned. This is supported by the fact that two thirds of the employees surveyed as part of this research, believe that the existing dimensions are appropriate. It is also clear that The Organisation understands the link between employee satisfaction and customer satisfaction (as described by Heskett et al, 1994) as it makes a point of measuring both of these aspects on an on-going basis. What is not very clear is whether all the managers in the region fully appreciate the significance of ensuring satisfied employees. This is supported in the feedback received that the original purpose for the strategy has long since been forgotten. It is obvious that an opportunity is being missed by regional management in using a tool that generally is seen to be administered appropriately, measures the right dimensions and is regularly being completed by $50 \%$ of their employees on an annual basis.

There is, however, growing resistance from the staff to participate in the survey each year due to the fact that they very seldom ever receive any feedback regarding the results and certainly do not experience any consequences (positive or negative) as a result of the survey. This situation is, therefore, actually contributing to the dissatisfaction levels of the very people who are supposed to benefit from the process. The employees and managers have indicated support for the inclusion of comments fields in the assessment tool as well as the use of more open ended questioning techniques. This is a clear indication that a qualitative element should be included in the process of assessing and grappling with Employee Satisfaction.

It is understood that The Organisation requires a score to be generated to be used as one input in the process, but there is certainly support for a process being implemented to afford managers and staff an opportunity to get to grips with identifying and addressing the real needs of the employees. Staff also indicated that the mere fact that an assessment has been completed is certainly not proof of an effective Employee Satisfaction strategy. Line managers need to use the data generated via the assessment process to generate action plans to address identified development areas.

\section{Recommendations}

Companies must build their own models because customer satisfaction is only one variable in understanding the relationship between employee satisfaction, customer satisfaction, and financial performance. Moreover, each company must determine how it defines employee satisfaction and customer satisfaction, which can even differ between departments and business units within one company. (Corporate Executive Board, 2003, p.2)

Based on the findings as discussed in this article, it is clear that the existing tool - although already in use for many years - is still seen to be measuring appropriate dimensions. It is, therefore, not recommended that wholesale changes be made to the existing tool at this stage. It would be more appropriate to use the hard copy inputs from the next survey to carry out a Cronbach analysis to determine the reliability coefficient of the existing tool.

However, from a strategy point of view there are clear opportunities which need to be exploited. These include the following:

- The Employee Satisfaction assessment strategy must be shared with both managers and employees throughout the region via a multi-level communication strategy.

- The questionnaire should be available both electronically and in hard copy. However, hard copy questionnaires must be distributed to semi-literate employees via Human Resources Practitioners who will personally facilitate the completion of the questionnaires.

- A 50\% return must continue to be maintained.

- On completion of the survey, results must be presented to senior regional management and line managers must be allocated a period of two weeks to share the results with their staff. The Human Resources department must provide a presentation template and process guideline for line managers to use when giving feedback to the employees to ensure consistency.

- All line managers must develop consequence action items regardless of the result achieved i.e. a spirit of continuous improvement needs to prevail. 
- In addition the Human Resources department must establish Area Employee Satisfaction Focus Groups which will meet one month after the results have been communicated to get feedback regarding the process. These focus groups may be facilitated by a Human Resources Practitioner.

\section{Limitations of the Present Study}

The questionnaire used to assess the existing strategy and tool was developed by the researcher and evidence of it having been subjected to any reliability test is unavailable. This, by implication, makes the reliability of the results produced questionable (Walizer \& Wienir, 1978). However, it was decided to utilise the data generated as part of the data triangulation process.

It may be argued that five focus groups are not sufficient to obtain valid inputs. This is particularly so in respect of management focus groups where only one management focus group was conducted which consisted of six participants. This amounts to a sample of $8 \%$ of 74 managers employed in the region. Four focus groups were conducted with a total of 42 lower level employees which equates to a sample size of $3 \%$ of the regional complement of 1456. However, Calder (1977), maintains that if the facilitator can clearly anticipate what will be said next in a group there is a clear indication that sufficient groups have been conducted.

No analysis has been conducted to determine the reliability of the existing tool due to the unavailability of historical input data. The unavailability of historical data is a result of the tool being administered electronically and raw data is, therefore, only available to the external service provider who owns the software. A reliability analysis would have resulted in a far more robust assessment of the existing tool and would have enhanced the triangulation of research data considerably. At least it would have given an indication of whether the current results generated by the existing tool are an accurate reflection of employee satisfaction in The Organisation.

\section{Suggestions for Further Research}

Through the process of conducting the first stage data collection in preparation for writing this article, it has become very apparent that there is a need - as well as a tremendous opportunity - to carry out additional research in the area of Employee Satisfaction in The Organisation, specifically in terms of developing an appropriate assessment tool. Any future tool would need to effectively accommodate both quantitative and qualitative elements as well as the needs of various demographic dimensions. The project that underpins this article managed to identify important possible answers to the question, "Are they really satisfied"? In order to obtain maximum value from the above mentioned findings, a practical model needs to be developed to inform The Organisation's future Employee Satisfaction assessment strategy. This represents a clear opportunity to embark on a full scale project at doctoral level within The Organisation.

\section{REFERENCES}

Bailey, B. \& Dandrade, R. (1995). Employee Satisfaction + Customer Satisfaction = Sustained Profitability: Digital Equipment Corporation's Strategic Quality Efforts. In, Center for Quality of Management Journal. Retrieved 22 February 2006 from http://cqmextra.cqm.org/cqmjournal. nsf/reprints/rp05800

Bavendam, J. (2000). Managing Job Satisfaction Bavendam Research Incorporated Special Report. Retrieved 6 February 2006 from http://www.employeesatisfactions.com.

Benkenstein, R. (2006). Personal communications (email) on the subject of the Employee Satisfaction Index, specifically in pursuance of how the Index was constructed, normed and validated.
Boeree, C.G. (1998). Qualitative Methods Workbook. Retrieved 30 April 2006 from http://www.ship.edu/ cgboeree/ qualmeth.html

Brewster, C., Dowling, P., Grobler, P., Holland, P. \& Warnich, S. (2000). Comtemporary Issues in Human Resource Management: Gaining a Competitive Advantage. Oxford: Oxford University Press.

Bulgarella, C.C. (2005). Employee Satisfaction and Customer satisfaction: Is There a Relationship? Guidestar Research. Retrieved 2 May 2006 from http://www.guidestar. .com/professional_services/whitepaper_cs_es_relationships. pdf

Calder, B.J. (1977). Focus Groups and the Nature of Qualitative Marketing Research. In, Journal of Marketing Research, 14, 353-364.

Corporate Executive Board. (2003). Linking Employee Satisfaction with Productivity, Performance, and Customer Satisfaction Corporate Leadership Council. Retrieved 2 May 2006 from http://www.keepem.com/doc_files/clc_article_on_productiv ity.pdf

del Barrio, C. (1999). The Use of Semi-structured Interviews and Qualitative Methods for the Study of Peer Bullying. Universidad Autonome de Madrid. Retrieved 2 May 2006 from http://www.gold.ac.uk/tmr/reports/aim2 madrid1.html

Fosam, E.B., Grimsley, M.F.J. \& Wisher, S.J. (1998). Exploring models for employee satisfaction - with particular reference to a police force. In, Total Quality Management, 9 (2\&3), 235247.

Golafshani, N. (2003). Understanding Reliability and Validity in Qualitative Research. In, The Qualitative Report, 8 (4), 597607

Herzberg, F. (1968). One more time: How do you motivate employees? In, The Very Best of The Harvard Business Review of 1991, 119-130.

Heskett, J.L, Sasser, W.E. \& Schlesinger, L.A. (1997). The ServiceProfit Chain. New York: Free Press.

Ivancevich, J.M. \& Matteson, M.T. (2002). Organizational Behaviour and Management (6th Edition). New York: McGrawHill Irwin.

Janse van Rensburg, K. (2004). A Predictive Model of Employee Commitment in an Organisation Striving to Become World Class. Thesis submitted in fulfilment of the requirements for the degree D.Litt. Et Phil in Industrial Psychology in the Faculty of Arts at the Rand Afrikaans University.

Krauss, S.E. (2005). Research Paradigms and Meaning Making: A Primer. In, The Qualitative Report, 10 (4), 758-770.

Kraut, A.I. (1996). Organizational Surveys: Tools for Assessment and Change. San Francisco: Jossey-Bass Publishers.

Kreitner, B. \& Kinicki, A. (2005). Organizational Behaviour. Homewood: Irwin Incorporated.

Leones, J. (1998). A Guide to Designing and Conducting Visitor Surveys College of Agriculture Publications. Retrieved 1 September 2006 from http://ag.arizona.edu/pubs/ marketing/az1056/\#steps

Manicas, P. \& Secord, P. (1982). Implications for psychology of the new philosophy of science. In, American Psychologist, 38 390-413.

Martenson, A. \& Grønholdt, L. (2002). Using employee satisfaction measurement to improve people management: An adaptation of Kano's quality types. In, Total Quality Management, 12 (7\&8), 949-957.

Morgan, D.L. (1988). Focus Groups as Qualitative Research. Newberry Park: SAGE Publications. Inc.

Rosnow, R. \& Rosenthal, R. (1996). Beginning Behavioral Research. New Jersey: Prentice-Hall Inc.

Samuel, G. (2005). The Relationship Between Leadership and Internal Customer Satisfaction Within a Motor Manufacturing Company in Gauteng. Thesis submitted in partial fulfilment of the requirements for the degree of Masters in Business Administration of Rhodes University. 
Stoner, J.A.F. \& Wankel, C. (1986). Management. (3rd Edition) New Jersey: Prentice-Hall Inc.

Townsend, M. (2006a). "Are They Really Satisfied?" An Exploration of Issues Around Empoyee Satisfaction Assessment Strategies. Research proposal for the degree MPhil (L.P.C.) presented before the academic committee, DHRM, University of Johannesburg, on 26 May 2006.

Townsend, M. (2006b). Management Focus Group Data Collation. Collation of responses of focus group run on management level participants from The Organisation on 26 June 2006.

Townsend, M. (2006c). Employee Focus Groups Data Collation. Collation of responses from four focus groups held with employee level participants from The Organisation from 29 June 2006 to 11 August 2006.

Townsend, M. (2006d). Focus Group Response Analysis. A comparative analysis of the responses from Townsend (2006b) and Townsend (2006c).

Townsend, M. (2006e). Employee Satisfaction Survey Critique. An analysis of feedback received from an electronic survey conducted in July 2006.

Trochim, W.M.K. (2005). Qualitative Validity. One web page as downloaded from http://www.socialresearchmethods.net/ $\mathrm{kb} /$ qualval.htm on 20 Oct 2005.

Walizer, M. \& Wienir, P. (1978). Research Methods and Analysis: Searching for Relationships. New York: Harper and Row. 